\title{
EL PROYECTO DE ACTO LEGISLATIVO 192 DE 2012 Y EL DESARROLLO CONSTITUCIONAL
}

Brigadier General José Arturo Camelo Piñeros*

Respetados Señores y Señoras, Honorables Directivos, profesores y estudiantes de este claustro Universitario, compañeros panelistas, asistentes a ese evento académico:

Como ciudadano interesado en los temas que afectan la seguridad y defensa nacional, agradezco a los Directivos, docentes y organizadores de este espacio académico, la gentil invitación que me hicieran para participar con mis opiniones y observaciones en esta audiencia pública acerca de un tema tan trascendental para la paz de nuestra Nación.

Con base en la experiencia adquirida a través de 34 años de servicio a la Institución más respetada por el pueblo colombiano y especialmente por las reflexiones que avivaron en mi el comprender la situación crítica que vive la Justicia Penal Militar de nuestro País, puesto que me desempeñe como su Director durante los últimos 3 años de mi carrera, puedo manifestarles que no solo he sido testigo directo de la deformación, mas no transformación, del sistema de Justicia Penal Militar, sino un estudioso del caso, por lo que luego de mi retiro las circunstancias me han permitido la oportunidad de compartir conocimientos con funcionarios penales militares de diversos Países como Fiscal Consejero de la Asociación Internacional de Justicias Militares.

\footnotetext{
* Decano de la Facultad de Derecho, Escuela Militar de Cadetes “General José María Córdova".
} 
La brevedad del tiempo me obliga a prescindir de aspectos importantes que darían mayor ilustración acerca de la necesidad y fundamentos dogmáticos de un sistema adecuado de Justicia militar, por lo que debo referirme solo a los hechos mas recientes que generaron la inseguridad jurídica que soportan hoy los miembros de la Fuerza Pública.

Fue en el año 1993, cuando comenzó a tomar forma la crisis de la Justicia Penal Militar, cuando en obedecimiento a recomendaciones de la Corte Interamericana de Derechos Humanos, se declararon inconstitucionales las figuras del defensor militar, Fiscal Penal Militar y jurados de conciencia que conformaban los denominados consejos de guerra, mediante sentencias C-592 de 1993 y C- 141 de 1995. Como resultado, se llegó en aquel entonces a una conclusión absurda basada en la negación del principio de la buena fe, según la cual las cortes o tribunales militares de que trata nuestra Constitución Política en el artículo 221, no podían estar integrados por militares debido a que sus integrantes, como miembros activos de la Fuerza Pública, se encontraban investidos de un sentido de autoridad y obediencia incompatibles con los cargos para administrar justicia.

Para ese entonces emergió como salvador el Acto Legislativo $\mathrm{N}^{\circ} 2$ de 1995 el cual terminó adicionando al artículo 221 Constitucional, la obligatoriedad lógica de integrar dichas Cortes marciales o tribunales militares, con miembros de la Fuerza Pública en actividad o en retiro. Como complemento de lo anterior la sentencia C-145 de 1998 orientó y encargó al Congreso de la República para regular los juicios por jurado; pero, debido a que también era perentorio acatar otras recomendaciones que la Comisión Interamericana de Derechos Humanos había formulado desde 1981 y que tenían que ver con la independencia de las decisiones judiciales y sanción de conductas violatorias de los Derechos Humanos, en contravía de todo lo dispuesto por los legisladores al expedir el Acto Legislativo $\mathrm{N}^{\circ} 2$ y contrario a lo dispuesto por la honorable Corte Constitucional, se expidió el nuevo Código Penal Militar mediante Ley 522 de 1999, que por ser fiel copia del Código Ordinario eliminó los juicios por jurado y por ende las cortes marciales o tribunales militares, vigentes desde el inicio de la República. Para los interesados en desviar la atención sobre el caso, las cortes marciales — que deberían estar integradas por vocales o jurado, como elemento fundamental de un sistema de Justicia Penal Militar (el juicio de los pares) — aparecen en el Código Penal Militar actual confundidas con la audiencia oral. 
De forma simultánea, se originó la inseguridad jurídica laboral que aún persiste, puesto que si bien existen civiles que desempeñan cargos en la Justicia Penal Militar, ellos no podían ser desprovistos de sus cargos sin menoscabar sus derechos fundamentales por lo que la atención se centró, no en el desarrollo de una doctrina penal sino en la vigilancia de derechos laborales. Fue la sentencia C-171 de 2004 la que quiso definir en últimas los requisitos para desempeñar cargos en la Jurisdicción Penal Militar, en aplicación de un correcto entendimiento del Acto Legislativo $\mathrm{N}^{\circ} 2$ de 1995, y se fijaron entonces como requisitos esenciales el ser oficial de la Fuerza Pública en servicio activo o en retiro y ser abogado, queriendo explicar la necesidad de que para investigar, acusar y juzgar una conducta punible cometida en situaciones especiales del ámbito castrense, se requerían de manera simultánea conocimientos militares y jurídicos.

La sentencia exigía el cumplimiento de los requisitos que consideraba esenciales, pero como tabla salvadora de quienes vieron amenazada su estabilidad laboral, apareció por iniciativa del legislador un proyecto cuyo objeto consistió en determinar los requisitos para desempeñar cargos en la Justicia Penal Militar, en clara contraposición a lo determinado por la Alta Corte (Ley 940 de 2005).

La situación actual nos indica que lo que quiso definir y aclarar el Acto Legislativo $\mathrm{N}^{\circ} 2$ de 1995 luego de 17 años no se ha cumplido; la Justicia Penal Militar - en acatamiento de separar las funciones judiciales de las funciones de mando- se encuentra desvinculada de la Institución Militar, a quien debe su naturaleza y razón de ser, no existen las cortes marciales integradas por vocales o jurados, carece de credibilidad y eficiencia, los combatientes no son juzgados por sus pares y no existen mecanismos para hacer cumplir las decisiones constitucionales, ni existen sanciones por su incumplimiento.

Ahora bien, estamos frente a un nuevo proyecto de Acto Legislativo que pretende brindar seguridad jurídica a nuestros combatientes y que al tenor de su exposición de motivos se encuentra pleno de buenas intenciones, pero que, desafortunadamente, no corresponderá a la realidad.

En primer lugar, se dispone la integración de un tribunal de garantías penales con competencia en todo el territorio nacional y para actuar frente a cualquier jurisdicción y servir como juez de garantías, controlar las acusaciones penales en contra de los miembros de la 
Fuerza pública y dirimir conflictos de competencia. Aquí se puede apreciar que la intención es buena, pero su aplicabilidad dudosa, puesto que si el proyecto se refiere a la figura del juez de garantías del sistema acusatorio colombiano, las decisiones que debe tomar ese juez de garantías corresponderán a decisiones solicitadas por el Fiscal de cada caso para definir situaciones de manera diligente, so pena de vulnerar derechos fundamentales, tales como las medidas cautelares, legalizaciones de captura, formulaciones de imputación o definición de situación jurídica; lo que se ocasionaría en consecuencia sería una congestión que iría en contra de la seguridad jurídica que se pretende brindar. Resultaría difícil evitar las solicitudes de los defensores argumentando la necesidad de que sus casos sean definidos por el tribunal de garantías ante el más mínimo asomo de circunstancias adversas o ante posibilidades de dilatar procesos.

Por otro lado, debemos entender que las disposiciones de la Corte Constitucional, con base en el correcto entendimiento del artículo 221 superior, señalan la obligación de administrar justicia mediante la integración de cortes marciales o tribunales militares, lo cual nos remite a un sistema acusatorio puro propio de las justicias penales militares de la mayoría de países del mundo y que en consecuencia operan de manera diferente, sin que consideren la figura de un juez especial que avale las solicitudes de los fiscales, tal como opera en nuestro sistema penal ordinario. La integración del tribunal para el caso de la definición de los conflictos de competencia, se simplificaría si se incluyen los tres o cuatro magistrados con conocimientos jurídicos y militares al Consejo Superior de la Judicatura que mantiene esa función en el numeral 6 del artículo 256 constitucional.

La reforma del artículo 221 constitucional se refiere a múltiples objetivos. En primer lugar, con el argumento de brindar seguridad jurídica a los combatientes, se elevan a rango constitucional diversos delitos para ser excluidos del conocimiento de la Justicia Penal Militar, lo cual no resulta comprensible, no solo porque se le daría a la norma de normas un carácter subsidiario que bien le corresponde al Código Penal Militar sino porque, para la delicada función de calificar una conducta como delito de lesa humanidad con base en el mero conocimiento de los hechos- para determinar la competencia ab initio, no se determina a quien corresponderá, lo cual es una de las causas que originan la inseguridad jurídica que afecta al combatiente. 
Para el miembro de la Fuerza Pública desde su proceso de formación, es claro advertir que un delito de lesa humanidad, un genocidio, una tortura, una desaparición forzada o un delito sexual no será investigado por la Justicia Penal Militar. El problema para él es no tener la certeza de saber a quien corresponderá darle esa connotación cuando se refiera a hechos sucedidos en desarrollo de operaciones militares, porque la experiencia vivida en los últimos años le está indicando que al lugar de los hechos está acudiendo un conjunto de personas que no están en capacidad de analizar la circunstancias que se experimentan en una situación de combate. Aquí cabe anotar que este asunto tan importante, se encontraba definido en el artículo $2^{\circ}$ de la Ley 522 de 1999 (anterior Código Penal Militar), el cual disponía: “... de conformidad con las pruebas allegadas, la autoridad judicial que conoce del proceso determinará la competencia de acuerdo con las disposiciones constitucionales, legales y reglamentarias que regulan la actividad de la Fuerza Pública", artículo este que no fue incorporado inexplicablemente al nuevo Código Penal Militar, contenido en la Ley 1407 de 2010, a pesar de haber sido declarado exequible por la honorable Corte Constitucional mediante sentencia C-361 de 2001.

En segundo lugar, al artículo 221 se le pretende agregar, a manera de memorando a los jueces, tener en cuenta las normas del D.I.H. cuando se trate de investigar a miembros de la Fuerza Pública por conductas relacionadas con el conflicto armado, lo que aparece como innecesario, puesto que ya las existentes normas constitucionales obligan a tener en cuenta los tratados y convenios ratificados por el Congreso, dentro de los cuales se encuentran las normas de Derechos Humanos, el D.I.H. y el Estatuto de la Corte Penal Internacional. Así, no parece coherente remitir a una norma estatutaria normas que ya se encuentran reguladas en el Derecho Internacional por misma disposición de la Constitución Política, formando parte importante del denominado bloque de constitucionalidad.

En tercer lugar, aparece la conformación de una comisión adicional de carácter técnico integrada por cuerpos técnicos judiciales pertenecientes a cada una de las Jurisdicciones Penal y Penal Militar, para definir competencias en caso de duda, lo cual viene a sumarse al tribunal de garantías, sin perjuicio de la facultad que le corresponde al Consejo Superior de la Judicatura en el numeral 6 del artículo 256 superior. Debemos tener en cuenta que en la actualidad, la Justicia Penal Militar no cuenta con ese cuerpo técnico especializado y que su admisibilidad puede presentar fallas de institucionalidad ante la 
negativa de conceder funciones de Policía Judicial a los miembros de las Fuerzas Militares de acuerdo con recomendaciones de los organismos internacionales. La definición de competencia, tal como se ha sostenido anteriormente, debe ser definida por el funcionario judicial y no por un órgano de carácter técnico, una vez se tenga conocimiento de los hechos, con base en las pruebas allegadas y de acuerdo con las disposiciones constitucionales, legales y reglamentarias que regulan la actividad de la Fuerza Pública.

No aparece claro frente al artículo 221, el cual dispone la conformación de tribunales y cortes marciales por miembros de la Fuerza Pública, la intención de conformar la Justicia Penal Militar como una organización independiente del mando institucional. Nuevamente se cae en el error de que, pretendiendo separar funciones, se separen instituciones. Caso distinto, necesario y aplicable en sistemas penales militares de otros países es definir procedimientos y tipificar conductas punibles que contribuyan a prevenir y sancionar actos de intromisión en la administración de justicia y usurpación de funciones judiciales en asuntos judiciales.

La necesidad de la creación de un fondo destinado específicamente para financiar el sistema de defensa técnica especializada de los miembros de la Fuerza Pública aparece incontrovertible ante la evidente y vergonzante realidad de presenciar como los hombres sujetos a investigación penal por hechos sucedidos durante de sus funciones constitucionales, deben sufragar los gastos de la Defensoría Militar. En lo que respecta a la disposición según la cual los miembros de la Fuerza Pública deben cumplir su detención preventiva y pena en centros de reclusión establecidos para ellos, resulta igualmente necesaria, siempre y cuando ahora no se considere perdida esta garantía una vez se pase a la situación de retiro, sino su condición en el momento de la comisión de los hechos.

Teniendo en cuenta las recomendaciones del Dr. FernANDO VeLÁSQuEZ V., resumo así mi propuesta de acuerdo con lo planteado:

En primer lugar, considerar la posibilidad de integrar al Consejo Superior de la Judicatura los tres o cuatro magistrados con conocimiento militar, para su actuación en el análisis y definición de conflictos de competencia.

En segundo lugar, rescatar el artículo $2^{\circ}$ de la Ley 522 de 1999, declarado exequible por la honorable Corte Constitucional mediante 
Sentencia C-361 de 2001, el cual fijaba en cabeza del funcionario judicial, para que sea el funcionario judicial militar la autoridad en quien descanse la responsabilidad de definir la competencia para conocer $a b$ initio del proceso, sin perjuicio de los conflictos de competencia que puedan presentarse.

En tercer lugar, excluir del proyecto de Acto Legislativo la definición de los tipos penales que no son de conocimiento de la jurisdicción penal Militar.

En cuarto lugar, exigir el cumplimiento de la norma constitucional del artículo 221, y la sentencia C-145 de 1998, la cual dispone la integración de cortes o tribunales militares escabinados (mixtos), conformados por miembros de la Fuerza Pública en actividad o en retiro, para transformar las lamentables condiciones actuales del juzgamiento, mediante la participación de vocales o jurados que conozcan y comprendan las situaciones que se presentan en la ejecución de actos relacionados con el servicio, y juristas militares que aporten el conocimiento jurídico aplicable a las operaciones militares.

Por último, mantener lo dispuesto en relación con la creación de la defensoría militar y el fuero carcelario y en caso de archivarse el proyecto, para el primer caso disponerlo mediante la expedición de una ley ordinaria, y para lo segundo exigir lo que ya se encuentra dispuesto en la Ley 65 de 1.993. 
